\title{
AMENDMENTS
}

\section{Author Correction: Circumpolar projections of Antarctic krill growth potential}

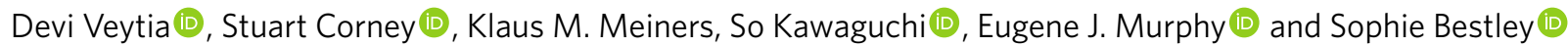

Correction to: Nature Climate Change https://doi.org/10.1038/s41558-020-0758-4, published online 18 May 2020.

In the version of this Article originally published, in the first sentence of the Data availability section, the link 'https://doi.org/10.26179/ 5e27c6584e0f8' was incorrect; it should have been 'https://doi.org/10.26179/p2e4-5695'. The online versions of the Article have been corrected.

Published online: 10 December 2020

https://doi.org/10.1038/s41558-020-00978-4

(c) The Author(s), under exclusive licence to Springer Nature Limited 2020

\section{Publisher Correction: Weakening Atlantic overturning circulation causes South Atlantic salinity pile-up}

Chenyu Zhu (iD) and Zhengyu Liu (i)

Correction to: Nature Climate Change https://doi.org/10.1038/s41558-020-0897-7, published online 14 September 2020.

In the version of this Letter originally published online, there was some incorrect information relating to $P$ values. In the sentences beginning "First, in historical simulations..." and "In all ten control simulations..., ' $P>0.1$ ' should have read ' $P<0.1$ '. In Fig. $3 \mathrm{~b}$ caption, in the sentence beginning “The black solid line represents..., ' $P=0.01$ ' should have read ' $P=0.1$ ', and in Fig. $3 c$ caption, in the sentence beginning "Correlation and linear regression analyses..., ' $P>0.01$ ' should have read ' $P<0.01$ '. Furthermore, in the sentence beginning "This salinity indicator differs from..., the second citation of 'Fig. 1a' should have been 'Fig. 1d,f'. In the sentence beginning "Given the robust AMOC slowdown...", the phrase "a remote an indicator of" should have read "a remote indicator of"; and the sentence "This circulation change can be contributed to substantially by the remote weakening of the AMOC, as discussed below." should have read "This circulation change is induced substantially by the weakening AMOC.. In the sentence beginning "This implies that a stronger AMOC slowdown...", the value " $2.3 \mathrm{~Sv}^{-1} / 0.1 \mathrm{psu}^{-1}$ " should have read " $2.3 \mathrm{~Sv} / 0.1$ psu". These errors have been corrected in all versions of the Letter.

Published online: 22 October 2020

https://doi.org/10.1038/s41558-020-00951-1

(c) The Author(s), under exclusive licence to Springer Nature Limited 2020 